\title{
Short term effects of intravenous pulses of cyclophosphamide in the treatment of connective tissue disease crisis
}

\author{
Hans-Jacob Haga, David D'Cruz, Ronald Asherson, Graham R V Hughes
}

\begin{abstract}
A predominantly outpatient regimen of low dose intravenous cyclophosphamide was used to treat patients with serious progressive connective tissue diseases. Fifty five patients were treated with a total of 211 intravenous pulses of cyclophosphamide. Forty five patients had previously shown no response to a variety of other treatments. Low dose intravenous cyclophosphamide $(500 \mathrm{mg}$ ) was given in 179 pulses and repeated pulses were given in most patients at weekly intervals for one to three weeks to induce disease remission. A good response was noted in 37 of 55 (67\%) patients assessed four weeks after the pulses. Only 20 patients needed more than one such course of three pulses of intravenous cyclophosphamide during the observation period. The non-responders were characterised by longstanding disease and irreversible histological findings in renal and muscle biopsy samples.

Patients with vasculitis, notably Wegener's granulomatosis, showed the most immediate response, and in most patients the amount of corticosteroids required was markedly reduced. In some patients steroids were completely stopped during the follow up period.

The most striking observation of this effective but more conservative regimen was the low incidence of major side effects such as neutropenia and infections. It is concluded that low dose pulses of intravenous cyclophosphamide are well tolerated and are an effective treatment for patients with aggressive connective tissue diseases.
\end{abstract}

(Ann Rheum Dis 1992; 51: 885-888)

The use of cyclophosphamide given by mouth in the treatment of some connective tissue diseases has resulted in a dramatic improvement in patient outcome. The one year survival rate of patients with Wegener's granulomatosis has been improved from $10 \%$ when not treated to more than $80 \%$ when treated. ${ }^{1-3}$ Cyclophosphamide is also well established in the treatment of lupus nephritis, where it reduces the risk of endstage renal failure. ${ }^{45}$ It has been reported to be effective in the treatment of some vasculitic syndromes ${ }^{6-10}$ and in active polymyositis. ${ }^{11}$ As a result of its serious adverse side effects, however, cyclophosphamide has generally been justified only in serious life threatening diseases and their complications.

Cyclophosphamide is usually given by mouth and the immunological and clinical responses occur after at least 10 days of treatment. ${ }^{7}$ 10 $12-14$
In patients with severe progressive systemic disease a rapid response to treatment may be crucial for the outcome and intravenous 'pulse' regimens have therefore been recommended when a rapid response is required. ${ }^{78}$ To date intravenous doses calculated on a surface area basis have tended to be high (of the order of $750-1250 \mathrm{mg}$ ) and the infection rate has consequently been high, in some series up to $25 \%$. $^{4}$ Observations in our lupus and vasculitis clinics at St Thomas's Hospital suggested that lower intravenous doses might have similar benefits with far less toxicity. In view of this and the potential advantage of being able to treat more patients on an outpatient basis we embarked on a treatment protocol initially using three weekly $500 \mathrm{mg}$ intravenous pulses of cyclophosphamide.

This paper reports our clinical experience using intravenous cyclophosphamide in 55 patients with connective tissue disease referred from all parts of the United Kingdom and treated with a total of 211 pulses in 105 courses. Low dose intravenous cyclophosphamide (500 $\mathrm{mg}$ ) was given in 179 of 211 pulses and pulses were usually repeated at weekly intervals to induce disease remission. Subsequent maintainance treatment was either with immunosuppressive drugs given by mouth or further pulses of cyclophosphamide given at monthly intervals.

Patients and methods

Table 1 gives the demographic data for these patients. The patients treated between April 1986 and April 1990 were all diagnosed as having serious progressive systemic diseases justifying treatment with intravenous cyclophosphamide. Forty five patients had previously not responded to treatment with prednisolone, 21 with azathioprine, eight with cyclophosphamide given by mouth, seven with methylprednisolone, four with antimalarial drugs, one with methotrexate, two with dapsone, one with penicillamine, and two with plasmapheresis either alone or in combination. The patients were followed up in the outpatients clinic for an average of 17 months (range $1-48$ months) after the first course of intravenous cyclophosphamide. Intravenous cyclophosphamide $(500 \mathrm{mg})$ was given in 100-500 ml saline, and each infusion was administered over one hour and was accompanied by vigorous hydration by mouth to promote frequent voiding of dilute urine in the first 24 hours after drug administration. To reduce bladder toxicity further, uromitexan (Mesna $100 \mathrm{mg})^{1516}$ was given in 200 of 211 pulses intravenously at the start of
G R V Hughes Dr Hughes.

Accepted for publication 31 December 1991 
Table 1 Diagnosis and demographic features of 55 patients treated with intravenous pulses of cyclophosphamide

\begin{tabular}{llll}
\hline Diagnosis & $\begin{array}{l}\text { No of } \\
\text { patients }\end{array}$ & $\begin{array}{l}\text { Mean age } \\
\text { (range) (years) }\end{array}$ & $\begin{array}{l}\text { Male:female } \\
\text { ratio }\end{array}$ \\
\hline Systemic lupus erythematosus & 30 & $34 \cdot 7(21-61)$ & $1: 29$ \\
Wegener's granulomatosis & 13 & $44.3(18-73)$ & $6: 7$ \\
Polyarteritis nodosa & 2 & $45 \cdot 5(41-50)$ & $1: 1$ \\
Systemic vasculitis & 3 & $45 \cdot 7(34-54)$ & $0: 3$ \\
Polymyositis/dermatomyositis & 7 & $49 \cdot 0(24-64)$ & $2: 5$ \\
\hline
\end{tabular}

the infusion of intravenous cyclophosphamide, followed by $200 \mathrm{mg}$ by mouth four and eight hours later. Two further pulses were given at seven day intervals. All patients were treated with antiemetics. Blood samples were collected one week after each pulse (before the subsequent pulse). In 28 of 211 pulses cyclophosphamide was given as $250 \mathrm{mg}$ ( 21 pulses), $750 \mathrm{mg}$ (six pulses), or $100 \mathrm{mg}$ (one pulse) doses intravenously. The patients were subsequently treated either with azathioprine $(2 \mathrm{mg} / \mathrm{kg} / \mathrm{day})$, cyclophosphamide by mouth $(2 \mathrm{mg} / \mathrm{kg} /$ day $)$, or continued to have monthly pulses of cyclophosphamide depending on the clinical severity of the disease. Clinical evaluations were carried out during the four weeks following the first pulse. Student's paired and non-paired $t$ tests and Wilcoxon's rank sum tests were used for statistical evaluation.

\section{Results}

GENERAL EFFECTS

Disease remission or definite improvement in disease activity was noted in 37 of 55 patients within four weeks of the start of intravenous cyclophosphamide treatment. The best response was seen in patients with Wegener's granulomatosis and most of these patients began to respond within the first week of pulse treatment. Striking improvements were also noted after two to four weeks in three patients with acute polymyositis confirmed by biopsy. Surprisingly, striking improvement was also seen in three of five patients with peripheral neuropathy and two of three patients with cutaneous ulcers and threatened gangrene due to vasculitis. The erythrocyte sedimentation rate was significantly reduced from 62 (SD 33) to $47 \mathrm{~mm}$ in the first hour $(p<0.001)$ during the four week observation period.

A small number of patients did not respond within the first four weeks of pulse cyclophosphamide treatment. These included one patient with lupus psychosis, one with epilepsy associated with cerebral lupus, four patients with pulmonary fibrosis, and one with antiphospholipid syndrome. Patients with irreversible chronic or fibrotic changes, or both, in renal and muscle biopsy samples did not respond to treatment.

\section{INTRAVENOUS CYCLOPHOSPHAMIDE AND} DIAGNOSIS

Systemic lupus erythematosus

Thirty patients with SLE were treated with pulses of cyclophosphamide with a mean of 3.5 pulses (range one to nine) and with a mean cumulative dose of $1.6 \mathrm{~g}$ (range $0 \cdot 5-4 \cdot 5$ ). All met at least four of the American Rheumatism Association criteria for the classification of SLE. ${ }^{13}$ Twenty four patients had lupus nephritis with persistent proteinuria or abnormal urine sediments, which was confirmed by renal biopsy in 22. Eight patients had renal impairment. Histology showed six biopsy samples with focal proliferative nephritis (WHO grade III), 15 with diffuse proliferative lupus nephritis (WHO grade IV), and one with membranous nephritis (WHO grade V). In most of these patients the four week observation period was too short to see any dramatic changes in renal function, though two patients with renal impairment improved with decreases in the mean creatinine level from 487 to $273 \mu \mathrm{mol} / \mathrm{l}$. The longer term follow up of these patients has been encouraging and has been reported elsewhere. ${ }^{14}$

There was rapid improvement in all five patients with SLE with fever and all three with active serositis. All seven patients with SLE with cutaneous vasculitis responded rapidly to treatment within one to two weeks.

\section{Systemic vasculitis}

Thirteen patients with Wegener's granulomatosis, two with polyarteritis nodosa, and three with systemic vasculitis were included in the study. They were treated with a mean of $4 \cdot 7$ pulses (mean 1-17) and had a mean cumulative dose of $2.3 \mathrm{~g}$ cyclophosphamide (range 0.5 $8 \cdot 5$ ). In patients with Wegener's granulomatosis the mean cumulative dose of intravenous cyclophosphamide $(2.8 \mathrm{~g})$ and the mean number of pulses $(6 \cdot 4)$ were higher compared with the other patients in the study, reflecting aggressive and relapsing disease in many of these patients. Most patients responded promptly to treatment within two weeks and there was a dramatic improvement in all eight patients with cutaneous vasculitis, and six patients with fever, one with serositis, one with peripheral neuropathy, two with acute pulmonary infiltrates, five with ear, nose, and throat symptoms, one with acute deafness due to vasculitis, and one with loss of vision due to large granulomatous masses in the orbits. In this last patient sight was restored within the first two weeks of treatment and the orbital masses decreased in size over the following four months of treatment with pulse cyclophosphamide. Two patients with Wegener's granulomatosis had renal failure and their serum creatinine concentrations decreased from 478 to 396 and from 471 to $226 \mu \mathrm{mol} / \mathrm{l}$, respectively, within four weeks of the start of treatment with weekly doses of intravenous cyclophosphamide. Significant haematuria $(4+)$ in dipstick testing in one patient with normal renal function was reduced to microscopic haematuria after three weekly pulses of intravenous cyclophosphamide.

\section{Polymyositis/dermatomyositis}

Seven patients with polymyositis and dermatomyositis were treated with a mean of 3.6 pulses (range 2-5) and had a mean cumulative dose of cyclophosphamide of $1.6 \mathrm{~g}$ (range $0 \cdot 8-2.5 \mathrm{~g}$ ). 
Table 2 Adverse effects of pulse cyclophosphamide treatment

\begin{tabular}{lll}
\hline Adverse effects & $\begin{array}{l}\text { No of } \\
\text { patients }\end{array}$ & Comments \\
\hline $\begin{array}{l}\text { Nausea } \\
\text { Allergic reactions } \\
\text { Infections }\end{array}$ & $\begin{array}{l}\text { All } \\
2\end{array}$ & $\begin{array}{l}\text { Relieved by antiemetics } \\
\text { Result of treatment with Mesna } \\
\text { Aspergillus with pseudomonas, } \\
\text { pneumonia, Siaphvlococcus aureus }\end{array}$ \\
$\begin{array}{l}\text { impetigo, Gram negative septicaemia } \\
\text { (fatal), Salmonella tvphimurium sepsis, } \\
\text { herpes \%oster }\end{array}$ \\
$\begin{array}{l}\text { Neutropenia }\left(<2000 \times 10^{9} / 1\right) \\
\text { Therapeutic abortion }\end{array}$ & 5 & Pregnancy test positive after first pulse \\
$\begin{array}{l}\text { Facial warts } \\
\text { Haemorrhagic cystitis }\end{array}$ & 1 & Mesna omitted inadvertently \\
\hline
\end{tabular}

Table 3 Effect of weekly intravenous pulses of cyclophosphamide (500 mg) on white blood cells and platelets in patients treated with one, two, and three pulses. The cell numbers are given as mean (SD) $10^{9} / l$ and were counted immediately before the start of pulses, one week after the first and second pulse, and two weeks after the third pulse

\begin{tabular}{|c|c|c|c|c|}
\hline & $\begin{array}{l}\text { Before } \\
\text { pulses }\end{array}$ & $\begin{array}{l}\text { After one } \\
\text { pulse }\end{array}$ & $\begin{array}{l}\text { After two } \\
\text { pulses }\end{array}$ & $\begin{array}{l}\text { After three } \\
\text { pulses }\end{array}$ \\
\hline $\begin{array}{l}\text { Total no of } \\
\text { white blood cells } \\
\text { Neutrophils } \\
\text { Lymphocytes } \\
\text { Platelets }\end{array}$ & $\begin{array}{l}10 \cdot 3(6 \cdot 0) \\
(n=37) \\
7 \cdot 0(4 \cdot 3) \\
(n=25) \\
1 \cdot 7(1 \cdot 5) \\
(n=25) \\
361(153) \\
(n=35)\end{array}$ & $\begin{array}{l}9 \cdot 9(5 \cdot 1) \\
(n=34) \\
8 \cdot 3(4 \cdot 9) \\
(n=25) \\
1 \cdot 7(1 \cdot 3) \\
(n=26) \\
360(145) \\
(n=32)\end{array}$ & $\begin{array}{l}8 \cdot 1(4 \cdot 7) \\
(n=21) \\
7 \cdot 1(4 \cdot 3) \\
(n=14) \\
1 \cdot 5(1 \cdot 2) \\
(n=15) \\
372(144) \\
(n=25)\end{array}$ & $\begin{array}{l}7 \cdot 4(4 \cdot 5) \\
(n=17) \\
5 \cdot 2(3 \cdot 3) \\
(n=10) \\
1 \cdot 3(0 \cdot 9) \\
(n=11) \\
337(124) \\
(n=20)\end{array}$ \\
\hline
\end{tabular}

Four patients responded to treatment with two to five weekly pulses of intravenous cyclophosphamide, showing an objective improvement in muscle strength. Weekly serial myometry scores were obtained using the same seven muscle groups in each patient and the mean (SD) scores improved from 71.5 (50) to $100 \cdot 8(65) \mathrm{N}$ after the initial four weeks of treatment ( $p<0.0001$, Wilcoxon's signed rank test). After pulse treatment, these patients were treated either with low dose prednisolone $(15-25 \mathrm{mg})$ in combination with azathioprine or cyclophosphamide by mouth. These patients continued to improve over the next six months and all have recovered completely. Three non-responders were either terminally ill, had long standing disease without an increase in muscle enzymes, or fat replacement in the muscle biopsy sample.

ADVERSE EFFECTS OF PULSE CYCLOPHOSPHAMIDE Table 2 shows the main adverse effects noted in our series of patients treated with pulses of cyclophosphamide. A total of five of $55(9 \%)$ patients had infectious complications, one of which was fatal. In this patient the combination of renal failure, recent treatment with azathioprine, and pulse cyclophosphamide may have induced the neutropenia and the fatal gram negative septicaemia. Nausea was universal, though not severe, and was usually amenable to treatment with antiemetics. Menstrual irregularities were only noted in patients receiving long term treatment with cyclophosphamide by mouth, not in association with pulse treatment. No patient treated with pulse cyclophosphamide alone developed amenorrhoea. No adverse effect on liver function tests was observed as a result of the pulse treatment.
Haematological side effects

Table 3 shows that the neutrophil and lymphocyte counts were marginally reduced after two pulses followed by a more marked, but not statistically significant, decrease seen two weeks after the third pulse. A non-significant increase of neutrophils from 7.0 to $8.3 \times 10^{9}$ cells/l was seen one week after the first pulse. Five patients developed lymphopenia $(<1500 \times$ $10^{9} / 1$ ) during treatment or within two weeks of the last pulse in a course. There was no correlation between either the cumulative dose of intravenous cyclophosphamide or the number of pulses and development of lymphopenia and neutropenia and apart from one patient with severe neutropenia the effect of intravenous cyclophosphamide on the white blood cells was reversible. Two patients who developed severe leucopenia followed by septicaemia had been treated for lupus nephritis and renal failure with azathioprine and intravenous cyclophosphamide. Thirty two patients were lymphopenic before pulse treatment and 22 remained lymphopenic. In the only patient with neutropenia before treatment (a patient with SLE) the number of neutrophils increased from $1300 \times 10^{9} / 1$ to more than $2000 \times 10^{9} / 1$ after pulse treatment. Significant thrombocytopenia $\left(<150 \times 10^{9} / 1\right)$ was not induced by low dose pulses in any patient. Two patients were thrombocytopenic before pulses, but intravenous cyclophosphamide had no effect on their platelet number.

\section{Discussion}

In this study we observed a remarkably rapid response to intravenous cyclophosphamide in patients with systemic necrotising vasculitis, cutaneous vasculitis, and acute polymyositis. The clearest responses were seen in those patients with systemic vasculitides such as Wegener's granulomatosis, polymyositis, and in patients with lupus nephritis. These patients were notable because 45 of 55 had previously not responded to a variety of other treatments and because of the low incidence of adverse effects in this group of severely ill patients.

Intravenous cyclophosphamide is known to be better tolerated than cyclophosphamide by mouth $^{15}{ }^{17-19}$ and high doses of steroids ${ }^{15}$ 19-21 which are the usual alternatives. Nevertheless the previously published regimens, often requiring doses in excess of 1 or $1.5 \mathrm{~g}$, have been associated with important side effects, with infections in up to $10 \%$ and Herpes zoster in as many as $25 \% .^{+}$Our initial experience suggested that lower doses might be therapeutically beneficial but with far fewer side effects and better tolerance for outpatient use.

In this study using our ' $\mathrm{St}$ Thomas's Hospital regimen' of three weekly $500 \mathrm{mg}$ intravenous pulses, neutropenia was rare. Lymphopenia and neutropenia induced by treatment was seen in only five of 105 courses of intravenous cyclophosphamide. The two serious episodes of lymphopenia and neutropenia followed by septicaemia may have also been associated with renal failure previously treated with azathioprine and intravenous cyclophosphamide. Lympho- 
penia was reversible in all five patients in whom it occurred.

Infectious complications were seen in $7 \cdot 6 \%$ of our patients with lupus nephritis, though one patient died of a major infection. Herpes zoster was seen in only one patient. Infectious complications using low dose intravenous cyclophosphamide are therefore less common than reported for patients with lupus nephritis treated with higher doses of intravenous cyclophosphamide. ${ }^{4}$

In a large prospective study ${ }^{4}$ it was concluded that the treatment of lupus nephritis with intravenous cyclophosphamide every third month together with low dose prednisolone reduced the risk of end stage renal failure, and that this treatment was superior to the alternative using high dose prednisolone or azathioprine by mouth. In another study treating lupus nephritis with low dose intravenous cyclophosphamide once a month, ${ }^{22}$ the urinary excretion of protein was reduced and creatinine clearance improved after six months of treatment, but the improvement in renal function was not reflected by a decrease in serum creatinine. By giving weekly low dose intravenous cyclophosphamide we found that serum creatinine levels began to decrease within four weeks of treatment in two patients with SLE with focal proliferative glomerulonephritis (WHO grade III) and two patients with Wegener's granulomatosis and renal failure.

We believe that this large preliminary study shows that low dose pulse cyclophosphamide regimens offer clear advantages over previously published regimens in the treatment of patients with active connective tissue diseases.

1 Walton E W. Giant cell granuloma of the respiratory tract (Wegener's granulomatosis). BMY 1958; ii: 265-70.

2 Fauci A S, Haynes B F, Katz P, Wolff S M. Wegener's granulomatosis. Prospective clinical and therapeutic granulomatosis. Prospective clinical and therapeutic
experience with 85 patients for 21 years. Ann Intern Med 1983; 98: $76-85$.
3 Weiner S R, Paulus H E. Treatment of Wegener's granulomatosis with cyclophosphamide: an outcome analysis. matosis with cyclophosphamide: 39

4 Austin H A, Klippel J H, Balow J E, et al. Controlled trial of prednisone and cytotoxic drugs. $N$ Engl f Med 1986; 314: prednis.

5 Balow J E, Austin H A, George C T, Antonovych T T, Steinberg A D, Klippel J H. NIH conference: lupus nephritis. Ann Intern Med 1987; 106: 79-94.

6 Fauci A S, Haynes B F, Katz P. The spectrum of vasculitis. Clinical, pathologic, immunologic, and therapeutic considerations. Ann Intern Med 1978; 89: 660-76.

7 Cupps T R, Fauci A S. The vasculitides. In: Major problems in internal medicine. Philadelphia: Saunders, Vol. XXI. 1981: 155-72.

8 Scott D G, Bacon P A. Intravenous cyclophosphamide plus methylprednisolone in treatment of systemic rheumatoid methylprednisolone in treatment of syst

9 Leib E S, Restivo C, Paulus H E. Immunosuppressive and corticosteroid therapy of polyarteritis nodosa. Am $7 \mathrm{Med}$ 1979; 67: 941-7.

10 Fauci A S, Katz P, Haynes B F, Wolff S M. Cyclophosphamide therapy of severe systemic necrotising vasculitis. $N$ Engl $\mathcal{F}$ Med 1979; 301: 235-8.

11 Bombardieri S, Hughes G R V, Neri R, et al. Cyclophosphamide in severe polymyositis. Lancet 1989 ; i: 1138 .

12 Kinlen L J, Schell A G R, Peto J, et al. Collaborative United Kingdom-Australian study of cancer in patients treated with immunosuppressive drugs. $B M 7$ 1979; ii: 1461-6.

13 Tan E M, Cohen A S, Fries J, et al. The 1982 revised criteria for the classification of systemic lupus erythematosus. Arthritis Rheum 1982; 25: 1271-7.

14 Houssiau F A, D'Cruz D, Haga H-J, Hughes G R V. Short course of weekly low-dose intravenous pulse cyclophoscourse of weekly low-dose intravenous pulse cyclophos-
phamide in the treatment of lupus nephritis. Lupus 1991; 1 phamide

15 Pederson-Bjergaard J, Ersboll J, Hansen V L, et al. Carcinoma of the urinary bladder after treatment with cyclophosphamide for non-Hodgkin's lymphoma. N Engl f Med 1988; 318: 1028-32.

16 Bryant B M, Jarman M, Ford H T, et al. Prevention of ifosphamide-induced urothelial toxicity in 2-mercaptoethane sulphonate sodium (Mesnum) in patients with advanced carcinoma. Lancet 1980; ii: 657-9.

17 Currey H L F, Harris J, Mason R M, et al. Comparison of azathioprine, cyclophosphamide and gold in the treatment of rheumatoid arthritis. BMF 1974; iii: 763-6.

18 Bradley J, Brandt K D, Kat: B P. Infectious complications of cyclophosphamide treatment for vasculitis. Arthritis Rheum 1989; 32: 45-53.

19 Clements P J, Davis J. Cytotoxic drugs: their clinical application to the rheumatic diseases. Semin Arthritis Rheum 1986; 15: 231-54.

20 David D S, Grieco M H, Cushman P Jr. Adrenal glucosteroids after twenty years: a review of their chemically relevant consequences. F Chronic Dis 1970; 22: 637-711.

21 Kass E H, Finland $M$. Corticosteroids and infections. $A d v$ Intern Med 1958; 9: 45-80.

22 McCune W J, Golbus J, Zeldes W, Bohlke P, Dunne R, Fox D A. Clinical and immunological effects of monthly administration of intravenous cyclophosphamide in severe administration of intravenous cyclophosphamide in severe 1423-31. 